\title{
Um modelo da maturidade da gestão da demanda: Um estudo multicaso na cadeia de suprimento de produtos de mercearia básica
}

\author{
Demand management maturity model: $A$ multi case study in the \\ supply chain of grocery products
}

\author{
Daniela de Castro Melo ${ }^{1}$ \\ Rosane Lúcia Chicarelli Alcântara²
}

\begin{abstract}
Resumo: A gestão da demanda deve equilibrar as necessidades dos clientes com as capacidades da empresa, reduzindo incertezas, resultando em fluxos mais eficientes na cadeia de suprimentos. $\mathrm{O}$ objetivo deste estudo foi propor um modelo para analisar a maturidade do processo de gestão da demanda na cadeia de suprimentos de produtos de mercearia básica. Espera-se que o modelo resultante possa subsidiar as empresas a se estruturarem e desenvolverem competências para atingir maturidade no processo de gestão da demanda. Para tal, realizou-se um estudo multicaso que envolveu 22 empresas, dentre as quais: indústrias fornecedoras de produtos de mercearia básica, atacadistas distribuidores e supermercados. Foram realizadas observações diretas e 33 entrevistas nestas empresas. A pesquisa possibilitou estruturar um modelo de maturidade em gestão da demanda composto de quatro estágios divididos em nove dimensões: compartilhamento de informações; planejamento de ações conjuntas; execuções de ações conjuntas; interações inter e intraempresas; indicadores de desempenho; envolvimento da alta gerência; segmentação de clientes; segmentação de fornecedores; tecnologia da informação. Este modelo pode permitir às empresas identificar em qual estágio se encontram e em qual dimensão precisam focar seus esforços. Cada uma das dimensões representa um meio para que as empresas possam se estruturar e otimizar a rentabilidade por meio da melhoria da eficiência e da eficácia na cadeia de suprimentos.
\end{abstract}

Palavras-chave: Gestão da Demanda. Gestão da Cadeia de Suprimentos. Atacadista. Indústria mercearil. Supermercado.

\begin{abstract}
The purpose of demand management is to balance the needs of customers with the company's capabilities, reducing uncertainty, and providing efficient flow through the supply chain. The aim of this study was to propose a model to analyze demand management maturity process in the supply chain of grocery products. It is expected that the resulting model can subsidize companies to structure and develop skills to reach maturity in demand management process. To this end, a multi-case study was conducted involving 22 companies: grocery industries, supermarkets, and wholesale distributors. Direct observations and 33 interviews were carried out in these companies. The research allowed us to structure a maturity model for demand management that consists of four stages divided into nine dimensions: information sharing, joint planning, joint execution actions, inter and intra-company interactions, performance indicators, involvement of senior management, customer segmentation, supplier segmentation, and information technology. This model enables companies to identify the stage they are in and the dimension they need to focus their efforts. Each dimension represents a means to enable companies to structure themselves and optimize profitability by improving efficiency and effectiveness in the supply chain.
\end{abstract}

Keywords: Demand Management. Supply Chain Management. Wholesaler. Grocery industry. Retailer.

\section{Introdução}

A gestão da demanda é um tema emergente no campo de conhecimento da gestão da cadeia de suprimentos. Consiste em balancear e alinhar estrategicamente a demanda com a capacidade operacional ao longo da cadeia de suprimentos por meio da rápida e adequada integração das necessidades originadas do mercado na direção dos fornecedores.
Rexhausen, Pibernik e Kaiser (2012) ressaltam que uma gestão da demanda eficiente impacta de forma positiva e substancial o desempenho da cadeia de suprimentos como um todo, e consideram como dimensões da gestão da demanda a segmentação da demanda, a previsão de demanda, o Planejamento de Vendas e Operações (S\&OP - Sales and Operations

\footnotetext{
Departamento de Engenharia de Produção, Universidade Federal do Triângulo Mineiro - UFTM, Av. Doutor Randolfo Borges Júnior, 1250, Bairro Univerdecidade, CEP: 38064-200, Uberaba, MG, Brasil, e-mail: daniela_c_melo@ yahoo.com.br

${ }^{2}$ Departamento de Engenharia de Produção, Universidade Federal de São Carlos - UFSCar, Rod. Washington Luís, Km 235, CEP 13560-000, São Carlos, SP, Brasil, e-mail: rosane@dep.ufscar.br
}

Recebido em Maio 13, 2013 - Aceito em Maio 6, 2014

Suporte financeiro: Universidade Federal de Uberlândia - UFU. 
Planning) e a adesão à gestão da demanda. Isso porque, estes autores defendem que a implementação da segmentação da demanda, da previsão de demanda e do S\&OP podem não ser suficientes para uma empresa alcançar desempenho superior em gestão da demanda. Assim, destacam que o nível de adesão aos processos da gestão da demanda, que pode ser traduzido em processos bem definidos, implementados e rigorosamente cumpridos, desempenha um papel importante no desenvolvimento de capacidades superiores em empresas interessadas na implantação ou melhoria do processo de gestão da demanda.

A existência de um modelo, composto de estágios de evolução pelos quais o processo de gestão da demanda deve passar, pode auxiliar na análise do processo de gestão da demanda de uma empresa, gerando resultados que se traduzem em melhorias na eficiência e eficácia da organização.

Porém a literatura não apresenta nenhum modelo de maturidade que ajude a desenvolver nas empresas competências em gestão da demanda. Constatou-se, em pesquisa bibliográfica sistematizada, que existe pouca informação disponível sobre a gestão da demanda em cadeias de suprimentos (ADEBANJO, 2009; MELO; ALCÂNTARA, 2011, 2012; REXHAUSEN; PIBERNIK; KAISER, 2012; TAYLOR, 2006; TAYLOR; FEARNE, 2006; TROQUE, 2003). As abordagens de gestão da demanda identificadas na literatura (CROXTON et al., 2008; ESPER et al., 2010; HILLETOFTH; ERICSSON; CHRISTOPHER, 2009; JUTTNER; CHRISTOPHER; BAKER, 2007; MENTZER; MOON, 2005; VOLUNTARY..., 2010) não exploraram empiricamente as variáveis envolvidas para a implementação do processo de gestão da demanda.

Neste contexto, Croxton et al. (2008) desenvolveram um modelo conceitual para a implementação bem sucedida da gestão da demanda, porém não forneceram evidência empírica para o modelo proposto. Autores como Esper et al. (2010), Hilletofth, Ericsson e Christopher (2009), Juttner, Christopher e Baker (2007), Mentzer e Moon (2005), Voluntary Interindustry Commerce Standards - VICS (2010) propuseram abordagens para a gestão da demanda na cadeia de suprimentos destacando suas interações e sua importância, porém não apresentaram os passos para sua implantação, nem os indicadores de desempenho para sua avaliação.

Percebe-se que as contribuições da literatura geralmente focam práticas isoladas de gestão da demanda como previsão de demanda; planejamento de vendas e operações (S\&OP); planejamento, previsão e reposição colaborativos (CPFR); segmentação da demanda (MELO; ALCÂNTARA, 2011, 2012). Desta forma, a evidência empírica de algum impacto positivo da gestão da demanda no desempenho da cadeia de suprimentos é geralmente escassa e tem, em sua maioria, caráter conceitual (BOWER, 2006; MILLIKEN, 2008).

Diante da necessidade levantada por diversos autores (ADEBANJO, 2009; KAIPIA; KORHONEN; HARTIALA, 2006; MELO; ALCÂNTARA, 2011, 2012; MENTZER; MOON, 2005; REXHAUSEN; PIBERNIK; KAISER, 2012; SIMATUPANG; SRIDHARAN, 2002; TAYLOR, 2006; TAYLOR; FEARNE, 2006; TROQUE, 2003) de trabalhos que explorem de forma mais ampla o conceito de gestão da demanda, o objetivo deste trabalho é propor um modelo para analisar a maturidade do processo de gestão da demanda na cadeia de suprimentos de produtos de mercearia básica que envolva os elos indústria, atacadista distribuidor e lojas varejistas, para subsidiar as empresas a se estruturarem e desenvolverem competências para atingir maturidade em gestão da demanda. Este modelo visa auxiliar empresas a desenvolverem ações prospectivas para melhor atender aos clientes e assim possibilitar, com a sua adequada implantação, o aumento da rentabilidade por meio da melhoria da eficiência e da eficácia dos processos.

Desta forma, foi realizado um estudo multicaso que envolveu 22 empresas, dentre estas indústrias fornecedoras de produtos de mercearia básica, atacadistas distribuidores e supermercados. Foram realizadas observações diretas e 33 entrevistas nestas empresas. Os dados foram submetidos à análise de conteúdo.

A importância e a contribuição desta pesquisa estão justificadas pelo fato de esta auxiliar as empresas dessa cadeia a identificar as variáveis envolvidas para o desenvolvimento conjunto de seus negócios, visando melhor atender à demanda e possibilitando o aumento da rentabilidade.

Assim sendo, espera-se contribuir para melhor compreensão e visão mais ampla da gestão da demanda que aponte caminhos a serem adotados pelas organizações para a superação dos desafios atuais de conciliar as necessidades dos seus clientes e as capacidades das suas cadeias de suprimento. Por fim, os resultados deste trabalho podem despertar o interesse de outros setores industriais a desenvolverem estratégias de gestão da demanda ou servir de benckmarking para a implantação da gestão da demanda com parceiros estratégicos na cadeia de suprimentos.

$\mathrm{O}$ artigo está estruturado em quatro partes. Inicialmente, o referencial teórico aborda a gestão da demanda no contexto da gestão da cadeia de suprimentos, como também apresenta o setor atacadista distribuidor. Na sequência, é apresentado o método de pesquisa e, em seguida, os seus resultados. Por fim, são apresentadas as conclusões. 


\section{Revisão teórica}

Este tópico inicialmente discute o conceito de gestão da demanda e os fatores que auxiliam as empresas a implantarem o processo para a gestão da demanda na cadeia de suprimentos. Na sequência, o setor atacadista distribuidor é contextualizado.

\subsection{A gestão da demanda na cadeia de suprimentos}

Os conceitos e objetivos da gestão da demanda discutidos por diversos autores (por exemplo, CROXTON et al. 2008; HILLETOFTH; ERICSSON, 2007; HILLETOFTH; ERICSSON; CHRISTOPHER, 2009; JUTTNER; CHRISTOPHER; BAKER, 2007; MENTZER et al., 2007; MENTZER; MOON, 2005; PIRES, 2009; RAINBIRD, 2004; VOLLMANN et al., 2004; WALTERS, 2006; WALTERS; RAINBIRD, 2004) pressupõem que a gestão da demanda envolve a criação de sinergias entre a gestão de operações e de marketing com objetivo de compreender o mercado e desenvolver ações sincronizadas com a estratégia da empresa, capacidade produtiva e atendimento das necessidades do consumidor final.

A revisão da literatura permitiu identificar os fatores que auxiliam as empresas a implantarem o processo para a gestão da demanda na cadeia de suprimentos (Figura 1). Cada um destes fatores será discutido a seguir.

- Cadeia de suprimentos colaborativa

Segundo Mentzer et al. (2001), a orientação para a cadeia de suprimentos é um pré-requisito para a gestão da cadeia de suprimentos que consiste no desenvolvimento de esforços colaborativos intra e interempresas. Estes esforços representam os elementos da colaboração que, conforme Chen, Daugherty e Roath (2009), Fawcett, Magnan e McCarter (2008), Holweg et al. (2005), Horvath (2001), Mentzer, Fonghin e Golicic (2000), Min et al. (2005), Sabath e Fontanella (2002), Simatupang e Sridharan (2002, 2004), Stank, Keller e Daugherty (2001) e Vieira, Yoshizaki e Ho (2009), são: compartilhamento de informações; planejamento e execução de ações conjuntas; compartilhamento de riscos, custos e ganhos; desenvolvimento de relacionamento interno e externo à organização; investimentos financeiros e não financeiros; definição e acompanhamento de indicadores de desempenho.

- Conhecimento das capacidades, restrições e oportunidades do mercado

Para a implantação da gestão da demanda, é necessário compreender o mercado (CROXTON et al., 2008; ESPER et al., 2010; HILLETOFTH; ERICSSON; CHRISTOPHER, 2009; JUTTNER; CHRISTOPHER; BAKER, 2007; MENTZER; MOON, 2005; RAINBIRD, 2004) por meio da análise das capacidades, restrições, oportunidades dos ambientes interno e externo à empresa. $\mathrm{O}$ conhecimento do mercado interno e externo à empresa ditará as diretrizes e práticas estratégicas e operacionais da organização.

- Conhecimento das diretrizes/práticas estratégicas e operacionais das empresas

Envolve compartilhar informações estratégicas e operacionais entre as empresas para conhecer as dificuldades e potencialidades do parceiro (VIEIRA; YOSHIZAKI; HO, 2009) e gerar informações de previsões de demanda e suprimentos (informações de capacidade, iniciativas, estratégias dos fornecedores, tecnologia, tendências do setor, nível de estoque, transporte, opções de armazenamento) (ESPER et al., 2010). Além disso, ter acesso à intenção estratégica do parceiro permite o conhecimento do objetivo de crescimento, obtenção de participação de mercado, melhoria dos serviços oferecidos (MIN et al., 2005).

- Desenvolvimento de equipes interfuncionais

O processo de gestão da demanda envolve uma equipe interfuncional composta por integrantes de diversos níveis e setores da organização, bem

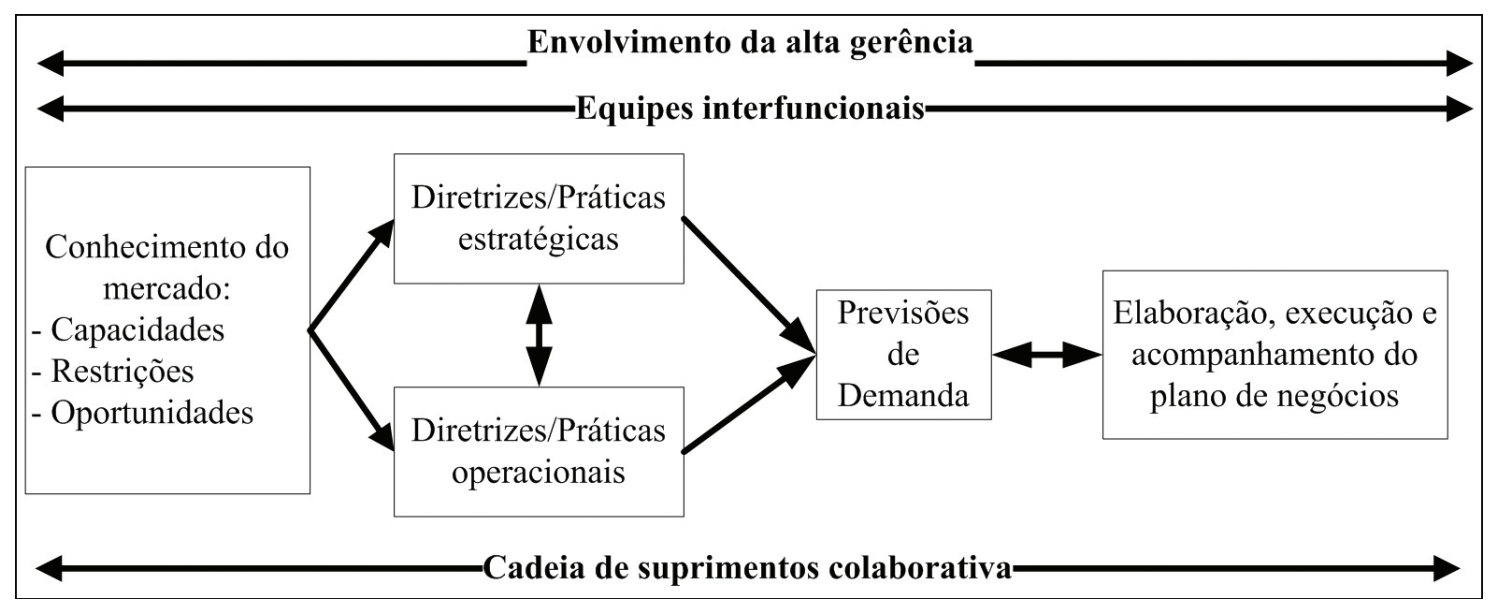

Figura 1. Fatores condicionantes para a gestão da demanda na cadeia de suprimentos. Fonte: Elaborado pelos autores. 
como representantes estratégicos da cadeia de suprimentos (fornecedores e clientes) (CHEN; DAUGHERTY; ROATH, 2009; CROXTON et al., 2008; HILLETOFTH; ERICSSON; CHRISTOPHER, 2009; JUTTNER; CHRISTOPHER; BAKER, 2007; MENTZER et al., 2007; VOLLMANN et al., 2004). Esta equipe interfuncional deve ter uma ampla compreensão do mercado, das diretrizes e práticas estratégicas e operacionais da organização (CROXTON et al., 2008; ESPER et al., 2010; HILLETOFTH; ERICSSON; CHRISTOPHER, 2009; MENTZER et al., 2007).

- Desenvolvimento de previsões de demanda

A previsão de vendas é a projeção para o futuro da demanda esperada (MENTZER et al., 2007) e tem por objetivo a acuracidade (MENTZER et al., 2007; TAYLOR; FEARNE, 2006). Segundo Croxton et al. (2008), para desenvolver as previsões, é necessário determinar o nível de detalhamento, abrangência da previsão, identificar as fontes de informação e definir o método de previsão, podendo envolver equipes interfuncionais interna e externa à empresa.

- Elaboração, execução e acompanhamento do plano de negócios

Constata-se que as empresas podem implantar diferentes níveis das iniciativas de S\&OP (Planejamento de Vendas e Operações) (GRIMSON; PYKE, 2007; LAPIDE, 2005), de CPFR (Planejamento, Previsão e Reposição Colaborativos) (DANESE, 2007; LARSEN; THERNOE; ANDRESEN, 2003; SEIFERT, 2003) e de VMI (Gerenciamento do Estoque pelo Fornecedor) (CLAASSEN; VAN WEELE; VAN RAAIJ, 2008; ELVANDER; SARPOLA; MATTSSON, 2007) na gestão da demanda.

Min et al. (2005) citam como uma das consequências da colaboração na cadeia de suprimentos, à medida que o relacionamento entre os parceiros melhora, o desenvolvimento de um plano de negócios conjunto que será executado pelas equipes interfuncionais de cada empresa. No contexto da gestão da demanda, Mentzer et al. (2007) conceituam "plano" como um conjunto de ações gerenciais específicas a serem tomadas para alcançar ou exceder as previsões de vendas. Diante das condições econômicas, da concorrência, dos planos de Marketing, Vendas, Produção e Logística, a projeção da demanda futura é realizada. Desta base, o plano de negócios é desenvolvido e este processo é iterativo, pois, se o plano de negócios resultante não estiver alinhado com as necessidades e objetivos financeiros da empresa, retorna-se à previsão de vendas, altera-se o plano de produção, vendas e estoques e examinam-se quais esforços adicionais podem ser realizados para alcançar o plano de negócios, garantindo, portanto, um plano baseado nas realidades financeiras e de mercado que a empresa enfrenta, nas capacidades logísticas e de produção, e da cadeia de suprimentos (MENTZER et al., 2007).

Por fim, o processo de colaboração deve ser formalizado detalhando as métricas de desempenho (MIN et al., 2005) que envolvem direcionamentos específicos em custos, produtividade e metas de ganhos. No processo de gestão da demanda, as equipes interfuncionais desenvolvem uma estrutura de indicadores para medir e monitorar o processo e estabelecem os objetivos para a melhoria de desempenho (CROXTON et al., 2008).

- Envolvimento da alta gerência

Para Min et al. (2005), o alinhamento interno envolve a determinação do que precisa ser feito internamente à organização e o que precisa ser cumprido pelos parceiros externos e, para garantir este alinhamento, é necessário o envolvimento da alta gerência. É importante o suporte de pessoas com poder de decisão para que ocorram investimentos financeiros e não financeiros. Além disso, para o compartilhamento de informações e comunicação entre os agentes da cadeia de suprimentos, é necessária a interação entre as altas gerências com objetivo de identificar oportunidades e áreas de melhorias (MIN et al., 2005).

Portanto, ao analisar a Figura 1, o processo de gestão da demanda envolve compreender o mercado por meio da análise das capacidades, restrições e oportunidades do ambiente externo. Este conhecimento do mercado, aliado às diretrizes e práticas estratégicas e operacionais da empresa, objetiva desenhar um sistema operacional eficiente para sincronizar demanda e suprimentos por meio das previsões de demanda. Para a elaboração destas, a empresa precisa ter uma orientação para a cadeia de suprimentos que consiste no estabelecimento de esforços cooperativos entre funções internas e agentes externos à empresa com o objetivo de atender às necessidades do consumidor final e obter vantagem competitiva.

Os planos de negócio são desenvolvidos com base na previsão de vendas feita por equipes interfuncionais das empresas da cadeia de suprimentos. Estas equipes também têm a responsabilidade pela execução e pelo acompanhamento do plano de negócios, buscando alternativas conjuntas para melhor atender ao cliente e redirecionar ações em situações divergentes do planejado. Todo o processo de gestão da demanda deve ser suportado pela alta gerência da empresa para garantir a implantação do processo com sucesso.

\subsection{O setor atacadista distribuidor}

Os atacadistas assumem a posse física dos bens e a propriedade, promovem o produto para possíveis clientes, negociam transações, financiam suas operações, põem em risco seu capital, processam pedidos e controlam pagamentos. Em geral, eles 
gerenciam os fluxos de informações nos dois sentidos: a montante para o fornecedor e a jusante para outros membros de canal e clientes futuros. E, ao fazerem isso, fornecem vantagens a montante e a jusante (COUGHLAN et al., 2002).

Verifica-se que, com a estabilidade econômica, o atacadista passou a ser um prestador de serviços de distribuição. Assim, além de armazenar mercadorias e lucrar com as vendas de produtos, suas atividades englobam agregar serviço e distribuição.

Segundo dados do Ranking ABAD/Nielsen (2013), o setor atacadista distribuidor representa $51,9 \%$ do mercado de consumo de varejo mercearil brasileiro. $\mathrm{O}$ setor atingiu um faturamento de $\mathrm{R} \$ 178,5$ bilhões em 2012, um crescimento de 8,5\% em comparação com o ano de 2011. Este resultado superou o crescimento da inflação de 5,8\%, de acordo com o IPCA - Índice de Preços ao Consumidor Ampliado, e do crescimento do PIB (Produto Interno Bruto) de $0,9 \%$ no mesmo período.

Empresas atacadistas distribuidoras enfrentam desafios da gestão da demanda diferentes dos da indústria. Por não terem um ambiente de transformação de produto, não tendo que lidar com questões de programação da produção, planejamento das necessidades de recursos e compra de matéria-prima, o setor necessita melhorar a colaboração na cadeia de suprimentos com seus elos da cadeia imediata (fornecedor e varejo) para desenvolver esforços conjuntos (ELOI, 2009; MIRANDA, 2005; MELO, ALCÂNTARA, 2012).

A expansão das grandes redes supermercadistas e as ações de pequenos e médios varejistas em busca de maior competitividade vêm alterando a estrutura da distribuição do País. Além disso, a indústria fornecedora, em busca de maior capilaridade de alcance dos seus produtos, investe e passa a exigir parceiros estratégicos para desenvolver as lojas varejistas. Atento a esses dois polos e, principalmente, às mudanças nos hábitos de consumo dos brasileiros, $\mathrm{o}$ segmento atacadista distribuidor necessita aperfeiçoar seus modelos de gestão para se adaptar às mudanças impostas pelo mercado, reduzindo custos e aumentando a eficiência na prestação de serviços, principalmente para pequenos varejistas (RANKING ABAD/ NIELSEN, 2013).

Desta forma, as exigências por variedade no ponto de vendas, melhor qualidade dos produtos e serviços ao cliente estão alterando a forma como o atacadista distribuidor administra seu negócio. $\mathrm{O}$ varejista não mais decide suas compras só com base na oferta do atacadista distribuidor, leva em conta também as expectativas do consumidor. Assim, a tradicional lógica de compra do atacadista e do varejista fortemente baseada em critérios centrados na relação quantidade e preço já não atende mais à dinâmica do mercado atual (ELOI, 2009; MIRANDA, 2005; SILVA; ALCÂNTARA, 2001).
Percebe-se então a evolução do pequeno varejo que desperta a necessidade de inovação do atacadista distribuidor e da indústria fornecedora para oferecer ao varejista um mix de produtos adequado, modernização de lojas e preços competitivos. Para atender às necessidades do pequeno varejo, $\mathrm{o}$ atacadista distribuidor e a indústria fornecedora estão desenvolvendo esforços conjuntos para alcançar seus objetivos estratégicos. Assim, compartilham informações, desenvolvem e implementam um plano de negócios conjunto e investem em recursos humanos e financeiros para preparar o pequeno varejista para o mercado competitivo (MELO; ALCÂNTARA, 2012).

O próximo tópico discute a metodologia utilizada para desenvolver esta pesquisa.

\section{Metodologia}

Tendo em vista que o tema deste trabalho está relacionado a um campo de pesquisa ainda em estágio de desenvolvimento, com múltiplas abordagens coexistindo, ausência de construtos conceituais comuns e envolvendo diversas disciplinas do conhecimento, como Marketing, Compras e Logística, entende-se que a estratégia de pesquisa mais adequada é a pesquisa qualitativa de natureza exploratória.

O método estudo de caso foi adotado nesta pesquisa. Segundo Yin (2005, p. 32),

[...] um estudo de caso é uma investigação empírica que investiga um fenômeno contemporâneo dentro do contexto da vida real, especialmente quando os limites entre fenômeno e contexto não estão claramente definidos.

A condução do estudo de caso envolveu a coleta de informações por meio de relatórios e documentos fornecidos pelas empresas, pelo material público divulgado na imprensa, por observações diretas e entrevistas.

Foi desenvolvido um roteiro de entrevista semiestruturado baseado na Revisão Sistemática da Literatura (MELO; ALCÂNTARA, 2011) e em pesquisas empíricas (MELO; ALCÂNTARA, 2012; REXHAUSEN; PIBERNIK; KAISER, 2012) com o objetivo de compreender o grau de sofisticação da gestão da demanda nas empresas pesquisadas, identificar as melhores práticas e os temas comuns nestas práticas. As questões do roteiro de entrevista foram estruturadas em tópicos conforme Quadro 1.

Assim, foram entrevistados executivos dos seguintes elos da cadeia de suprimentos:

- Fornecedores: foram envolvidas nove grandes empresas nacionais e multinacionais que manufaturam alimentos, bebidas, produtos de higiene, beleza e limpeza e que são fornecedoras das empresas atacadistas distribuidoras objetos desta pesquisa; 
Quadro 1. Tópicos e itens de cada tópico explorados nas entrevistas.

\begin{tabular}{|l|l|}
\hline $\begin{array}{c}\text { Tópicos explorados no roteiro de } \\
\text { entrevista }\end{array}$ & \multicolumn{1}{|c|}{ Itens de cada tópico } \\
\hline $\begin{array}{l}\text { Informações da empresa e função } \\
\text { do executivo }\end{array}$ & $\begin{array}{l}\text { Cidade, porte/faturamento, estrutura organizacional, mercado de atuação e } \\
\text { função do executivo. }\end{array}$ \\
\hline Planejamento da demanda & $\begin{array}{l}\text { Áreas/cargos envolvidos, fontes de dados utilizadas, como é realizada a previsão } \\
\text { de vendas, interações intra e interempresas, envolvimento da alta gerência, } \\
\text { compartilhamento de informações e tecnologia de informação utilizada. }\end{array}$ \\
\hline Execução do plano desenvolvido & $\begin{array}{l}\text { Indicadores de desempenho, reuniões de acompanhamento, envolvimento da } \\
\text { alta gerência, interações intra e interempresas, treinamento da força de vendas } \\
\text { e/ou lojas varejistas, gestão de estoques e tecnologia de informação utilizada. }\end{array}$ \\
\hline $\begin{array}{l}\text { Segmentação de clientes e/ou } \\
\text { fornecedores }\end{array}$ & Relacionamento com clientes e/ou fornecedores. \\
\hline $\begin{array}{l}\text { Dificuldades identificadas no } \\
\text { processo }\end{array}$ & Problemas/dificuldades percebidos no processo de gestão da demanda. \\
\hline
\end{tabular}

Fonte: Pesquisa de campo.

- Atacadistas distribuidores: foram envolvidas três grandes empresas atacadistas distribuidoras de atuação nacional localizadas na cidade de Uberlândia (MG), sendo uma delas líder nacional no setor;

- Lojas varejistas: dez supermercados de pequeno e médio porte que funcionam como redes interempresariais flexíveis com a atuação do atacadista distribuidor, detentor da marca da rede, para dar suporte para a modernização de seus negócios e serviços, foram envolvidos, sendo que somente as lojas varejistas, atendidas pelos atacadistas distribuidores, foram objetos desta pesquisa.

O Quadro 2 mostra os cargos entrevistados em cada um dos elos da cadeia de suprimentos. Desta forma, esta pesquisa envolveu 22 empresas, totalizando 33 entrevistas.

Johnson (2002, p. 113) afirma:

[...] o número de entrevistas necessárias para explorar uma determinada questão de pesquisa depende da natureza da questão e do tipo de conhecimento que o entrevistador procura.

Assim, o número ideal de entrevistas é o quanto o pesquisador ache suficiente para descobrir e verificar o que procura, inclusive retornando a alguns dos informantes em que mais confie ou que aparentemente detenham maior conhecimento sobre o assunto para esclarecer um tópico específico para o desenvolvimento de uma determinada categoria. A intenção, dessa forma, não é obter uma amostra significativa de uma população, mas sim escolher entrevistados com maior potencial de fornecer as informações desejadas.

A partir dessa orientação, com o objetivo de identificar os envolvidos no processo de gestão da demanda, como também verificar se o roteiro de entrevista estava adequado à realidade, os gerentes das áreas de Trade Marketing e Compras das empresas atacadistas distribuidoras foram contatados e convidados a participarem da pesquisa.

As primeiras entrevistas revelaram que as áreas envolvidas diretamente no processo de gestão da demanda nas empresas atacadistas são Trade Marketing e Compras. Assim, foram entrevistados representantes destas áreas nas três empresas atacadistas distribuidoras. Em duas empresas atacadistas distribuidoras, foram entrevistados dois gerentes de compras diferentes porque um é responsável pelas compras de produtos de higiene, beleza e limpeza e o outro, por produtos alimentícios. As áreas de Vendas e Logística não são envolvidas diretamente no planejamento das atividades de gestão da demanda, mas são impactadas pelas decisões relacionadas aos planos acordados, assim como são responsáveis pelo acompanhamento dos indicadores de desempenho. Portanto, as áreas escolhidas para as entrevistas nas empresas atacadistas distribuidoras foram Trade Marketing, Compras, Vendas e Logística.

Durante as entrevistas com os executivos das empresas atacadistas distribuidoras, foi solicitada a indicação de fornecedores que melhor desenvolvessem a gestão da demanda com as empresas atacadistas distribuidoras, como também seus respectivos contatos. Dentre as empresas fornecedoras indicadas, foram realizadas entrevistas com representantes das áreas Comercial e/ou Trade Marketing das empresas, pois estes estão diretamente envolvidos com o processo de gestão da demanda com as empresas atacadistas distribuidoras. Ao conduzir entrevistas com algumas empresas fornecedoras, os próprios executivos indicaram outros representantes de suas empresas que poderiam contribuir para a pesquisa. Os pesquisadores aproveitaram a abertura das empresas e entrevistaram os indicados, por esta razão alguns fornecedores têm mais de um representante. 
Quadro 2. Empresas pesquisadas e seus respectivos executivos entrevistados.

\begin{tabular}{|c|l|c|}
\hline \multicolumn{1}{|c|}{ Empresas } & \multicolumn{1}{|c|}{ Cargo dos entrevistados } & Entrevistas \\
\hline \multirow{5}{*}{ Atacadistas distribuidores } & Gerente de Compras & 5 \\
\cline { 2 - 3 } & Gerente de Vendas & 1 \\
\cline { 2 - 3 } & Gerente de Trade Marketing & 3 \\
\cline { 2 - 3 } & Gerente de Planejamento Logístico & 1 \\
\cline { 2 - 3 } & Gerente de Suprimentos & 1 \\
\cline { 2 - 3 } Fornecedores (Indústrias) & Total entrevistas atacadistas distribuidores & 1 \\
\hline & Supervisor de Vendas & 5 \\
\cline { 2 - 3 } & Gerente de Vendas & 1 \\
\cline { 2 - 3 } & Gerente Key Account & 3 \\
\cline { 2 - 3 } & Gerente de Trade Marketing & 1 \\
\cline { 2 - 3 } & Diretor de Planejamento da Demanda & $\mathbf{1 2}$ \\
\cline { 2 - 3 } & Total entrevistas fornecedores & 6 \\
\hline \multirow{5}{*}{ Lojas Varejistas } & Gerente Geral & $\mathbf{1 0}$ \\
\cline { 2 - 3 } & Gerente de Compras & $\mathbf{3 3}$ \\
\cline { 2 - 3 } & Total entrevistas lojas varejistas & \\
\hline Total geral de entrevistas & & \\
\hline
\end{tabular}

Fonte: Pesquisa de campo.

Todas as empresas fornecedoras entrevistadas estão lotadas administrativamente na cidade de São Paulo (SP), mas seus representantes comerciais e de trade marketing (supervisor de vendas, gerente de vendas, gerente key account, gerente de trade marketing) estão periodicamente visitando seus clientes atacadistas distribuidores. Assim, das 12 entrevistas realizadas com os fornecedores, somente duas foram realizadas na cidade de São Paulo: uma com o diretor de planejamento da demanda e a outra com o diretor de Trade Marketing \& Merchandising. As demais entrevistas com as empresas fornecedoras foram realizadas na cidade de Uberlândia (MG).

Ao finalizar as entrevistas com os atacadistas distribuidores e indústrias fornecedoras, foram selecionados, com base em critérios como acessibilidade e vínculo com os atacadistas distribuidores por meio das redes interempresariais, quinze supermercados localizados nas cidades de Uberaba (MG), Uberlândia (MG) e Patos de Minas (MG). Os pesquisadores entraram em contato e conseguiram entrevistar os gerentes gerais ou gerentes de compras de dez supermercados.

$\mathrm{O}$ uso do roteiro de entrevista semiestruturado permitiu fazer perguntas adicionais para elucidar questões que não ficaram claras ou ajudar a recompor o contexto da entrevista, principalmente em momentos em que os entrevistados perdiam o foco ou tinham dificuldade para expressar suas ideias.

Portanto, das 33 entrevistas, 25 foram realizadas na cidade de Uberlândia (MG), 2 em São Paulo (SP), 3 em Uberaba (MG) e 3 em Patos de Minas (MG). Esse processo se realizou no período compreendido entre fevereiro de 2011 e março de 2013, de acordo com a disponibilidade de tempo na agenda dos entrevistados. As entrevistas realizadas foram gravadas e transcritas integralmente, para posterior análise, acompanhadas de anotações efetuadas no caderno de campo, provenientes de observações dos pesquisadores e de diálogos informais mantidos com os entrevistados antes e depois das entrevistas. O tempo de duração média das entrevistas foi de uma hora e meia e as entrevistas envolveram dois pesquisadores.

Os dados obtidos foram submetidos à análise de conteúdo que, segundo Bauer (2002), consiste no estudo de transcrições textuais de dados visando comparar, observar diferenças e categorizar fatores presentes no texto por meio do processamento da informação.

As transcrições das entrevistas foram incluídas individualmente no programa NVivo10, como fontes documentais. Este programa é um aplicativo que possibilita a codificação de textos e gerenciamento das informações para apoio à análise dos dados. Suas funções permitem a divisão do texto em segmentos, a codificação desses segmentos e a explicitação de todas as instâncias codificadas.

Desta forma, à medida que a leitura atenta e cuidadosa de cada entrevista era efetuada, as ideias, conceitos ou aspectos relevantes para o tema da pesquisa foram sendo destacados e referenciados como códigos, com o apoio do programa utilizado. A análise das 33 entrevistas possibilitou a codificação de 844 referências passíveis de classificação nas categorias apresentadas no Quadro 3, bem como o número de referências obtidas. 
Quadro 3. Categorias de análise.

\begin{tabular}{|l|c|}
\hline \multicolumn{1}{|c|}{ Categorias } & Referências \\
\hline Compartilhamento de informações & 120 \\
\hline Planejamento de ações conjuntas & 89 \\
\hline Execuções de ações conjuntas & 75 \\
\hline Interações interempresas & 81 \\
\hline Interações intraempresas & 80 \\
\hline Indicadores de desempenho & 92 \\
\hline Envolvimento da alta gerência & 90 \\
\hline Segmentação de clientes & 72 \\
\hline Segmentação de fornecedores & 66 \\
\hline Tecnologia da informação & 79 \\
\hline Total de códigos & 844 \\
\hline
\end{tabular}

Fonte: Análise dos dados.

Mensagens por $e$-mail foram trocadas com alguns entrevistados, como também chamadas telefônicas foram realizadas para esclarecer algumas questões que não ficaram claras durante a análise dos dados.

O próximo tópico apresenta os resultados da pesquisa.

\section{Resultados}

As categorias identificadas na análise de conteúdo (compartilhamento de informações, planejamento de ações conjuntas, execução das ações conjuntas, interações interempresas, interações intraempresas, indicadores de desempenho, envolvimento da alta gerência, segmentação de clientes, segmentação de fornecedores e tecnologia da informação) foram inseridas no modelo de maturidade como dimensões a serem analisadas de cada estágio de maturidade. É importante destacar que as categorias 'interações interempresas' e 'interações intraempresas' foram agrupadas numa única dimensão para facilitar a descrição do modelo.

A análise das categorias permitiu agrupar as empresas pesquisadas em 4 estágios de maturidade em gestão da demanda: 1) empresas que ainda não possuem práticas de gestão da demanda e ainda não desenvolvem relacionamentos na cadeia de suprimentos. Desta forma, este estágio foi chamado de Transacional; 2) empresas que despertaram o interesse para a gestão da demanda na cadeia de suprimentos analisada, porém ainda não apresentam muitas práticas. Este estágio foi denominado Reativo; 3) empresas que estão desenvolvendo práticas de gestão da demanda na cadeia de suprimentos, aprimorando-as a cada ano. Assim, este estágio foi chamado de Desenvolvido; 4) empresas que estão mais avançadas em práticas de gestão da demanda. Este estágio foi denominado Avançado.

Assim, a análise dos dados possibilitou identificar um conjunto de características similares em determinadas empresas que possibilitaram estruturar um modelo de maturidade em gestão da demanda proposto no Quadro 4. Os detalhes de cada uma das dimensões e dos estágios serão discutidos na sequência.

\section{Estágio 1 - Transacional}

Foi possível identificar duas empresas varejistas neste estágio. Verifica-se que não há compartilhamento de informações tanto internamente quanto externamente à organização para a gestão da demanda. Nas duas empresas, a gestão da demanda é responsabilidade de uma área específica, geralmente a área Comercial que desenvolve as previsões de vendas, considerando um cenário demasiado otimista. Devido à capacidade de compras e/ou armazenagem dos produtos, a área de Logística ajusta as previsões desenvolvidas pela área Comercial. As previsões são estabelecidas para atingir os objetivos estratégicos, porém sem uma compreensão clara do mercado, capacidade de produto ou de armazenamento de mercadorias. Assim, falta consolidação da informação e diversas planilhas são mantidas por diferentes áreas.

Não existe um planejamento ou execução de ações conjuntas, cada área é independente e não há envolvimento de clientes ou fornecedores. Geralmente a alta gerência está preocupada se as vendas ocorridas atingiram o objetivo estratégico. Assim, o indicador de desempenho está focado no faturamento versus meta estabelecida.

Como são supermercados que utilizam a rede varejista do atacadista distribuidor, eles recebem deste o calendário de eventos, programam suas ações promocionais e desenvolvem suas previsões de vendas com base nas ações desenvolvidas pelos atacadistas distribuidores. Porém, não interagem com os fornecedores das indústrias ou atacadistas distribuidores.

Alguns entrevistados das empresas atacadistas distribuidoras e fornecedoras relataram que possuem dificuldade de implementar ações nestas empresas, pois elas não dão abertura para discutir as necessidades específicas da loja para promover as vendas.

Por fim, as empresas deste estágio não segmentam seus clientes e/ou fornecedores, relacionando-se da mesma forma com todos. Portanto, constata-se que a mentalidade funcional persiste neste estágio com pouca colaboração entre as áreas funcionais e entre empresas.

\section{Estágio 2 - Reativo}

Verificou-se que 8 empresas varejistas se encontram neste estágio e percebe-se que as práticas de gestão da demanda começam a se desenvolver. As áreas internas envolvidas no processo de gestão da demanda reúnem-se anualmente para desenvolverem um plano de negócios. Porém, verifica-se que os objetivos corporativos financeiros direcionam os esforços de vendas, atividades promocionais e decisões de preços, 


\begin{tabular}{|c|c|c|c|c|c|c|c|c|c|}
\hline 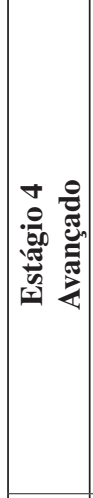 & 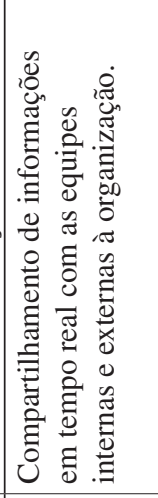 & 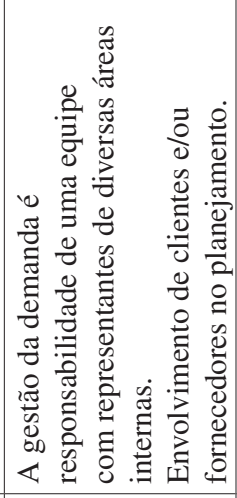 & 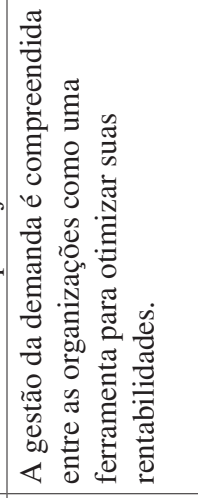 & 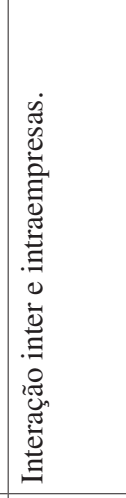 & 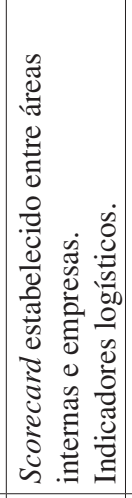 & 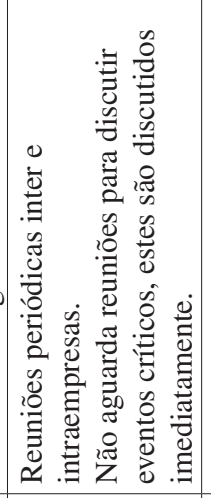 & 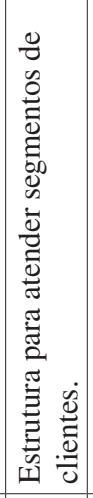 & 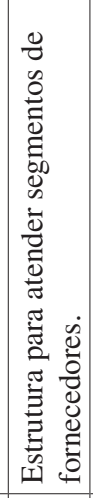 & 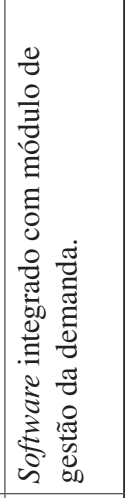 \\
\hline 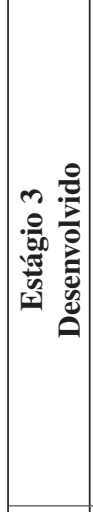 & 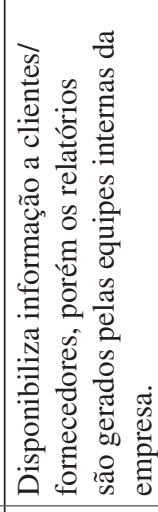 & 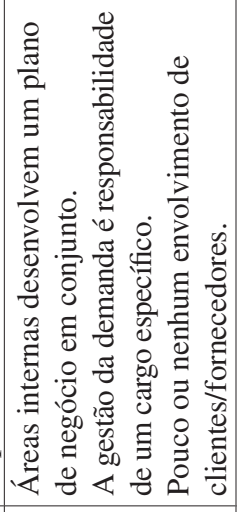 & 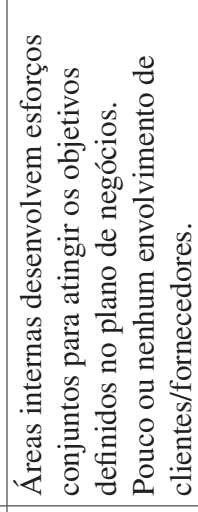 & 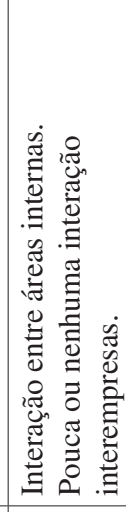 & 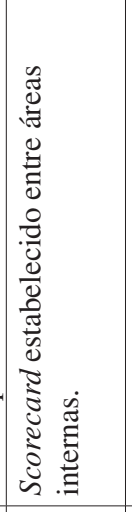 & 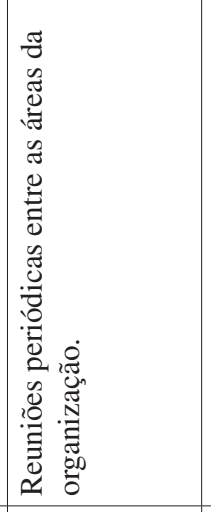 & 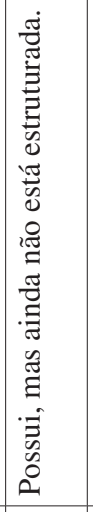 & 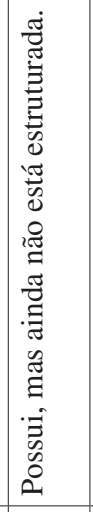 & 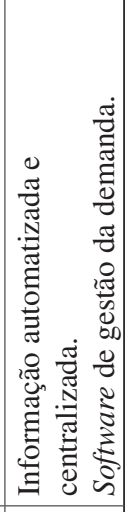 \\
\hline 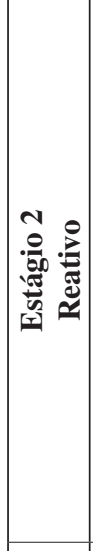 & 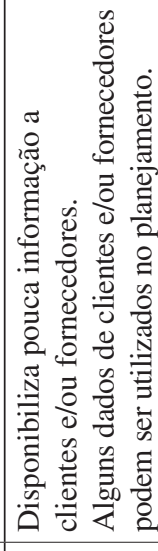 & 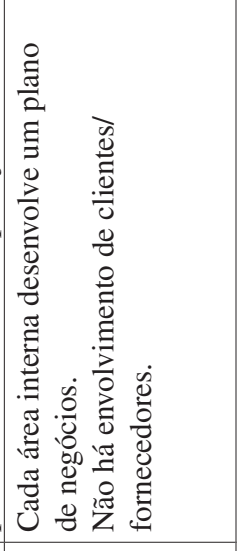 & 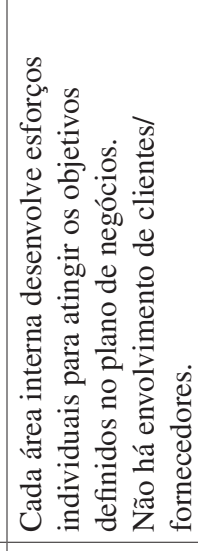 & 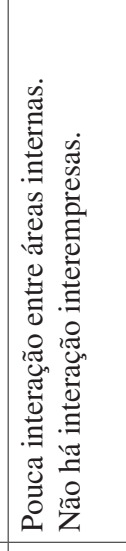 & 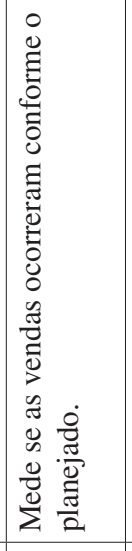 & 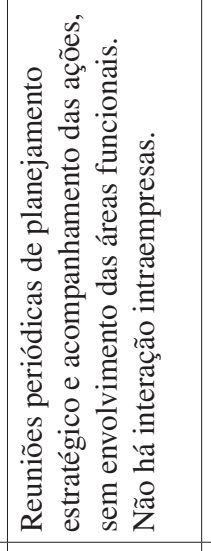 & 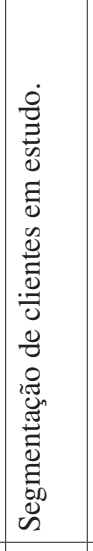 & 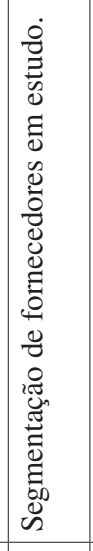 & 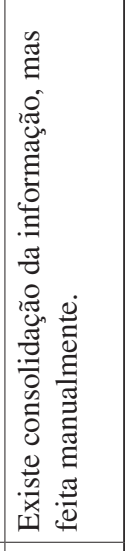 \\
\hline 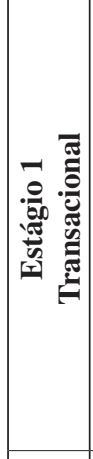 & 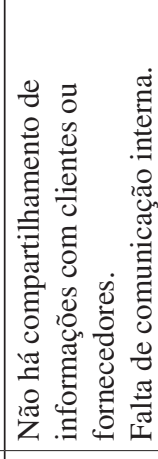 & 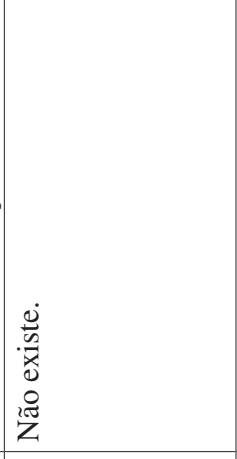 & 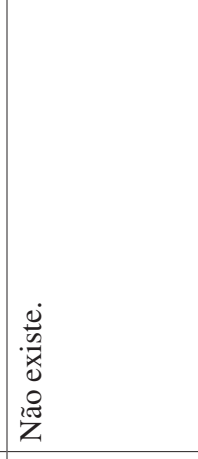 & 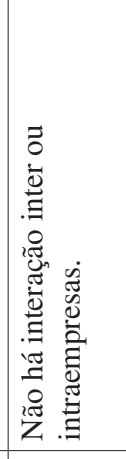 & 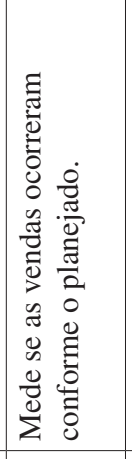 & 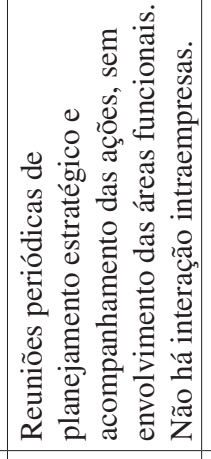 & 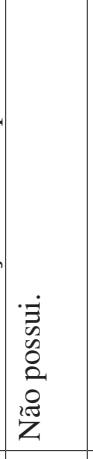 & 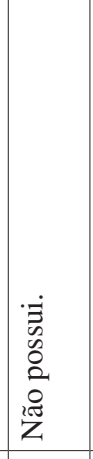 & 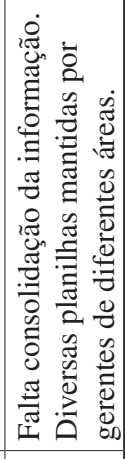 \\
\hline 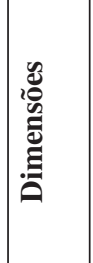 & 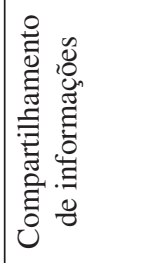 & 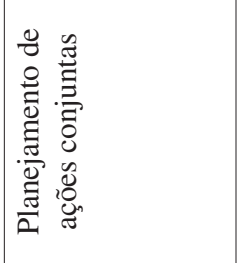 & 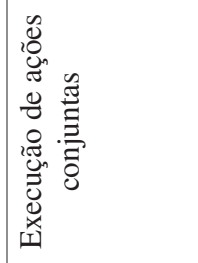 & 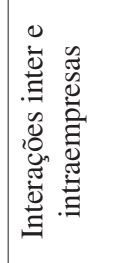 & 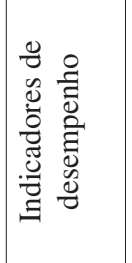 & 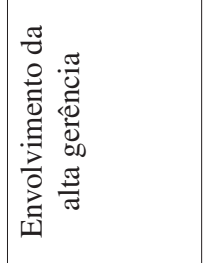 & 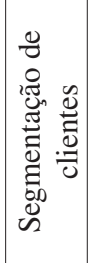 & 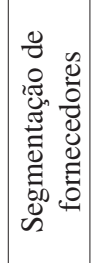 & 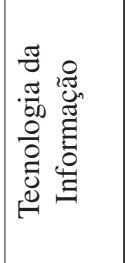 \\
\hline
\end{tabular}


sem uma compreensão clara do efeito no mercado ou nas operações das empresas.

Neste estágio ainda há pouca interação entre as áreas internas. Geralmente a área Comercial reúne-se com as empresas atacadistas distribuidoras para discutir a implementação de ações promocionais nas lojas e para acompanhar os resultados. As informações de vendas são consolidadas e compartilhadas com alguns atacadistas distribuidores. Assim, o principal indicador de desempenho é se as vendas ocorreram conforme o planejado.

Percebe-se que algumas empresas varejistas que se encontram neste estágio enxergam a necessidade de melhorar seus processos de gestão da demanda, estão aprendendo com os atacadistas e/ou fornecedores, mas ainda não se estruturaram para a mudança. Além disso, algumas possuem projetos, que se encontram em planejamento, de segmentar clientes e/ou fornecedores.

\section{Estágio 3 - Desenvolvido}

Encontram-se neste estágio três empresas fornecedoras que possuem baixa dependência do relacionamento com as empresas atacadistas distribuidoras. Apresentam vantagem de poder e estabelecem um plano de negócios para os atacadistas distribuidores com políticas de remuneração com base nas metas exigidas. Neste sentido, os atacadistas distribuidores precisam adaptar seus planos de negócio às exigências do fornecedor.

Também fazem parte deste estágio dois atacadistas distribuidores que se encontram na fase inicial de desenvolvimento da gestão da demanda com os fornecedores. As empresas compartilham o plano de negócios com alguns fornecedores, mas estes não são envolvidos no processo de formulação.

Desta forma, verifica-se que atacadistas distribuidores e fornecedores compartilham informações por meio de relatórios, mas não interagem para o desenvolvimento do plano de negócios em conjunto.

Percebe-se que nas empresas há alinhamento interno e as áreas desenvolvem anualmente um plano de negócio em conjunto, mas a gestão deste plano é responsabilidade de uma área específica, geralmente a área de Trade Marketing. As informações são centralizadas nesta área e automatizadas por meio de um software de gestão da demanda para o compartilhamento de informações de vendas e operações entre as equipes da organização e entre empresas.

As áreas internas estabelecem um scorecard para acompanhar o desempenho de vendas. Os principais indicadores são:

- Faturamento com o fornecedor/ atacadista distribuidor;

- Valor de vendas por categoria e subcategoria;
- Distribuição: número de lojas varejistas com vendas efetivadas;

- Volume de vendas por centro de distribuição;

- Valor em vendas por segmento de negócios;

- Valor em vendas por canal de vendas (internet, televendas, vendedores);

- Valor em vendas por áreas Nielsen.

Sobre este último tópico, deve-se esclarecer que a Nielsen, instituição que realiza pesquisas e oferece um conjunto integrado de dados do mercado às empresas, divide as regiões brasileiras em sete áreas geográficas:

- Área I: Ceará, Rio Grande do Norte, Paraíba, Pernambuco, Alagoas, Bahia e Sergipe;

- Área II: Minas Gerais, Espírito Santo, interior de Rio de Janeiro (excluindo-se os municípios contidos na Área III);

- Área III: Grande Rio de Janeiro: Rio de Janeiro, Niterói, Nova Iguaçu, Duque de Caxias, Nilópolis, São Gonçalo e São João de Meriti;

- Área IV: Grande São Paulo: São Paulo, Santo André, São Bernardo do Campo, São Caetano do Sul, Diadema, Mauá, Guarulhos, Osasco, Embu e Taboão da Serra;

- Área V: Interior de São Paulo (excluindo-se os municípios contidos na Área IV);

- Área VI: Paraná, Santa Catarina e Rio Grande do Sul;

- Área VII: Brasília, Mato Grosso do Sul e Goiás.

As reuniões entre as áreas de acompanhamento do plano de negócio estabelecido em conjunto geralmente ocorrem trimestralmente e envolvem a alta gerência, e podem incluir diretores e/ou vice-presidentes das áreas de Marketing, Vendas, Compras e Logística.

Os atacadistas distribuidores pertencentes a este estágio segmentam seus clientes por meio das redes supermercadistas, estabelecendo serviços diferenciados a estas lojas. Também segmentam seus fornecedores, estreitando relacionamentos com aqueles que apresentem relevância e rentabilidade do mix de produtos para o negócio dos atacadistas distribuidores, faturamento total anual e que investem recursos financeiros nas ações promocionais para as lojas varejistas.

Os fornecedores segmentam seus clientes com base no faturamento total anual e na capacidade de distribuição do atacadista distribuidor.

\section{Estágio 4 - Avançado}

Sete empresas, um atacadista distribuidor e seis fornecedores, encontram-se neste estágio, mas nenhuma envolveu ambos, clientes e fornecedores, no processo de gestão da demanda. Assim, o atacadista distribuidor desenvolve um plano de negócios em conjunto com os seus principais fornecedores, enquanto que os seis fornecedores elaboram um plano de negócios com seus principais clientes. 
As empresas não envolvem diretamente no processo de gestão da demanda as lojas varejistas, objetos desta pesquisa, porque suas equipes de vendas estão em constante contato com os varejistas, provendo as informações do ponto de vendas para o desenvolvimento do plano de negócios conjunto.

Neste estágio, as empresas compartilham informações em tempo real com equipes internas e externas à organização. Desta forma, não aguardam as reuniões periódicas para resolver os problemas que ocorrem, estes são direcionados imediatamente.

Apesar de as empresas que se encontram neste estágio possuírem um software integrado com módulo de gestão da demanda, elas não permitem a clientes ou fornecedores o acesso direto a este software. As equipes internas geram os relatórios solicitados por clientes ou fornecedores.

Os executivos das empresas se reúnem periodicamente com reuniões mensais entre as gerências das empresas, reuniões trimestrais com os diretores, reuniões semestrais envolvendo vicepresidências e/ou presidências.

Clientes e/ou fornecedores-chave participam do planejamento e da execução das ações estabelecidas no plano de negócios. As empresas segmentam seus fornecedores e clientes e estabelecem relacionamentos colaborativos com determinados segmentos.

Neste estágio, as empresas possuem equipes interfuncionais compostas por representantes das áreas de Marketing, Compras, Vendas e Operações (Produção e ou Logística), responsáveis pelas relações inter e intraempresas. Assim, estas equipes inicialmente alinham as diretrizes estratégicas das empresas, para então partirem para a formulação do plano de negócio em conjunto. O próximo passo envolve a execução e acompanhamento deste plano. Para acompanhar o desempenho, as empresas estabelecem um scorecard que envolve as seguintes medidas:

- Faturamento de vendas para o varejista e de compras do fornecedor, margem bruta, margem de contribuição;

- Valor em estoque, prazo médio de estoque, ruptura, capital de giro, tempo médio de entrega da mercadoria pelo fornecedor em relação ao prazo acordado e volume entregue em relação ao volume solicitado;

- Desempenho de vendas por categoria, centro de distribuição, segmento de negócios, canal de vendas, regiões Nielsen;

- Número de lojas varejistas com vendas efetivadas;

- Quantidade de itens por pedido.

$\mathrm{O}$ atacadista distribuidor segmenta seus clientes com base nas variáveis reciprocidade e necessidade de serviço. A reciprocidade se refere aos valores (em dinheiro) das transações comerciais com o varejista e à rentabilidade do atacadista distribuidor com estas transações. A necessidade de serviço está relacionada ao interesse das lojas varejistas em investir nos serviços oferecidos pela empresa tais como treinamentos, projetos de melhoria das lojas, serviços financeiros, desenvolvimento de campanhas de vendas e ações promocionais.

Os critérios das empresas para segmentar os fornecedores (no caso do atacadista distribuidor) e clientes (no caso dos fornecedores) são a relevância e rentabilidade do mix de produtos para o negócio das empresas, faturamento total anual com as empresas e nível de relacionamento. Este interesse se reflete na capacidade do fornecedor/atacadista distribuidor de trabalho em conjunto para desenvolver um plano de negócios, de planejamento e de investimento, como também na aproximação de equipes das duas empresas.

\section{Conclusões}

Este trabalho teve como objetivo propor um modelo para analisar o processo de gestão da demanda para subsidiar as empresas para se estruturarem e desenvolverem competências para atingir maturidade em gestão da demanda.

Neste sentido, a pesquisa possibilitou estruturar um modelo de maturidade em gestão da demanda composto de quatro estágios divididos em nove dimensões: compartilhamento de informações; planejamento de ações conjuntas; execuções de ações conjuntas; interações inter e intraempresas; indicadores de desempenho; envolvimento da alta gerência; segmentação de clientes; segmentação de fornecedores; tecnologia da informação.

Para avançar nos estágios, os profissionais das empresas devem focar inicialmente na interação interna entre as áreas envolvidas na gestão da demanda, para então, evoluir para interações entre empresas da cadeia de suprimentos.

Os resultados da pesquisa sugerem que as empresas supermercadistas, mesmo pertencentes a redes interempresariais, apresentam poucas práticas de gestão da demanda na cadeia de suprimentos e se encontram nos estágios iniciais de gestão da demanda. Enquanto que a maioria das indústrias fornecedoras se encontra em estágio avançado de gestão da demanda. Isto demonstra a importância das indústrias fornecedoras no compartilhamento de conhecimento e aprendizado para auxiliar outros agentes da cadeia de suprimentos a desenvolverem práticas de gestão da demanda. Além disso, ressalta a importância em estimular as lojas varejistas a aprimorarem suas práticas de gestão da demanda.

O modelo de maturidade em gestão da demanda permite às empresas identificar em qual estágio se encontram e em qual dimensão precisam focar seus esforços. Cada uma das dimensões representa um 
meio para que as empresas possam se estruturar e otimizar a rentabilidade por meio da melhoria da eficiência e da eficácia na cadeia de suprimentos.

A melhoria da eficiência é alcançada por meio do controle dos estoques e desenvolvimento de ações conjuntas quando o nível de inventário estiver elevado, refletindo em interações inter e intraempresas para desenvolver soluções conjuntas. Além disso, as empresas compartilham os custos e esforços para desenvolver iniciativas, campanhas de vendas e ações promocionais para a loja varejista e para a força de vendas. Outra melhoria se reflete no planejamento e controle da produção das empresas fornecedoras ao conseguirem uma previsão mais acurada da quantidade de matéria-prima que será necessária para atender à demanda, como também gera mais segurança para o atacadista distribuidor quanto à capacidade produtiva e de abastecimento do fornecedor.

A eficácia é obtida quando as empresas alcançam as metas estabelecidas de aumento de vendas e melhoria do nível de serviço. O crescimento das vendas se dá com o aumento do número de lojas varejistas que possuem os produtos dos fornecedores, sortimento e exposição dos produtos adequados no ponto de venda, melhoria na comunicação com a força de vendas e na sua capacitação para melhor atender às lojas varejistas. O nível de serviço melhora com a eliminação de deficiências nos processos, evitando as rupturas tanto no atacadista distribuidor quanto nas lojas varejistas. Neste sentido, as empresas buscam a interação entre suas equipes internas para que solucionem em conjunto os problemas. Por fim, as empresas têm oportunidade de compartilhar conhecimento e aprendizado, pois absorvem as melhores práticas de cada uma devido às constantes interações inter e intraempresas.

Foi evidenciado nesta pesquisa que as empresas não precisam obrigatoriamente implementar todas as variáveis de cada estágio, mas podem ter mais dificuldade em obter os resultados esperados se não implementá-las.

Portanto, a melhoria do processo de gestão da demanda na cadeia de suprimentos permite melhor visibilidade das diretrizes estratégicas de cada empresa, das tendências para o próximo ano, das previsões de vendas, a identificação de quais atividades norteiam o crescimento e o que as empresas precisarão investir para garantir este crescimento. Isto possibilita às empresas oferecer um melhor nível de serviço às lojas varejistas, atendendo conforme suas necessidades e evitando rupturas no ponto de vendas. Além disso, a gestão da demanda permite aos parceiros melhor controle de estoque, evitando rupturas no atacadista distribuidor e nas lojas varejistas.

Apesar de o modelo de maturidade em gestão da demanda apresentado neste estudo poder ser aplicado a outras cadeias de suprimentos, o estudo é limitado a uma cadeia específica e a abrangência de qualquer conceito ou experiência citada deve ser estudada de forma mais ampla. Além disso, a amostra desta pesquisa pode ser considerada limitada, pois foi pesquisado apenas o segmento de produtos de mercearia básica. Trabalhos futuros em gestão da demanda na cadeia de suprimentos poderiam ser realizados, abrangendo um estudo:

- Quantitativo que permita validar o modelo de maturidade em gestão da demanda proposto nesta pesquisa;

- Que envolva não somente redes supermercadistas interempresariais com a atuação do atacadista distribuidor;

- Em outros setores industriais para fins de análises comparativas;

- Em grandes redes de supermercados ou um número maior de cadeias de suprimentos ou que analisasse outros elos da cadeia de suprimentos.

\section{Agradecimentos}

Agradecimentos à Universidade Federal de Uberlândia pelo auxílio financeiro.

\section{Referências}

ADEBANJO, D. Understanding demand management challenges in intermediary food trading: a case study. Supply Chain Management, v. 14, n. 3, 2009. http:// dx.doi.org/10.1108/13598540910954566

BAUER, M. W. Análise de conteúdo clássica: uma revisão. In: BAUER, M. W.; GASKELL, G. (Ed.). Pesquisa qualitativa com texto, imagem e som. Petrópolis: Vozes, 2002. Manual prático.

BOWER, P. How the S\&OP process creates value in the supply chain. Journal of Business Forecasting, v. 25, p. 20-32, 2006.

CHEN, H.; DAUGHERTY, P. J.; ROATH, A. S. Defining and operationalizing supply chain process integration. Journal of Business Logistics, v. 30, n. 1, 2009. http:// dx.doi.org/10.1002/j.2158-1592.2009.tb00099.x

CLAASSEN, M. F. T.; VAN WEELE, A. F.; VAN RAAIJ, E. M. Performance outcomes and success factors of vendor managed inventory (VMI). Supply Chain Management: An International Journal, v. 13, n. 6, p. 406-414, 2008. http://dx.doi.org/10.1108/13598540810905660

COUGHLAN, A. T. et al. Canais de marketing e distribuição. 6. ed. São Paulo: Bookman, 2002.

CROXTON, K. L. et al. Supply Chain Management: Processes, Partnerships, Performance. Florida: Supply Chain Management Institute, 2008. p. 87-104.

DANESE, P. Designing CPFR collaborations: insights from seven case studies. International Journal of Operations \& Production Management, v. 27, n. 2, 2007, p. 181-204. http://dx.doi.org/10.1108/01443570710720612

ELOI, C. Análise ranking. Revista Distribuição, v. 196, n. 17, 2009. 
ELVANDER, M. S.; SARPOLA, S.; MATTSSON, S. A. Framework for Characterizing the Design of VMI Systems. International Journal of Physical Distribution and Logistics Management, v. 37, n. 10, p. 782-798, 2007. http://dx.doi.org/10.1108/09600030710848914

ESPER, T. L. et al. Demand and supply integration: a conceptual framework of value creation through knowledge management. Academy of Marketing Science, v. 38, n. 1, 2010.

FAWCETT, S. E.; MAGNAN, G. M.; MCCARTER, M. W. A three-stage implementation model for supply chain collaboration. Journal of Business Logistics, v. 29, n. 1, 2008. http://dx.doi.org/10.1002/j.2158-1592.2008. tb00070.x

GRIMSON, J. A.; PYKE, D. F. Sales and operations planning: an exploratory study and framework. International Journal of Logistics Management, v. 18 , n. 3 , p. 322-346, 2007. http://dx.doi. org/10.1108/09574090710835093

HILLETOFTH, P.; ERICSSON, D. Demand chain management: next generation of logistics management. Conradi Research Review, v. 4, n. 2, 2007.

HILLETOFTH, P.; ERICSSON, D.; CHRISTOPHER, M. Demand chain management: a Swedish industrial case study. Industrial Management and Data Systems, v. 109, n. 9, 2009. http://dx.doi. org/10.1108/02635570911002261

HOLWEG, M. et al. Supply chain collaboration: making sense of the strategy continuum. European Management Journal, v. 23, n. 2, 2005. http://dx.doi.org/10.1016/j. emj.2005.02.008

HORVATH, L. Collaboration: the key to value creation in supply chain management. Supply Chain Management: An International Journal, v. 6, n. 5, 2001.

JOHNSON, J. M. In-depth interviewing. In: HOLSTEIN, J. A.; GUBRIUM, J. F. (Ed.). Handbook of interview research: context \& method. Thousand Oaks: Sage Publications, 2002. p. 103-119.

JUTTNER, U.; CHRISTOPHER, M.; BAKER, S. Demand chain management-integrating marketing and supply chain management. Industrial Marketing Management, v. 36, 2007.

KAIPIA, R.; KORHONEN, H.; HARTIALA, H. Planning nervousness in a demand supply network: an empirical study. International Journal of Logistics Management, v. 17, n. 1, 2006. http://dx.doi. org/10.1108/09574090610663455

LAPIDE, L. Sales and operations planning Part III: a diagnostic model. Journal of Business Forecasting, v. 24, n. 1, p. 13-16, 2005.

LARSEN, T. S.; THERNOE, C.; ANDRESEN, C. Supply chain collaboration: theoretical perspective and empirical evidence. International Journal of Physical Distribution \& Logistics Management, v. 33, n. 6, p. 531-549, 2003. http://dx.doi.org/10.1108/09600030310492788

MELO, D. C.; ALCÂNTARA, R. L. C. A gestão da demanda em cadeias de suprimentos: uma abordagem além da previsão de vendas. Gestão \& Produção, v. 18, n. 4, p. 1-16, 2011. http://dx.doi.org/10.1590/ S0104-530X2011000400009
MELO, D. C.; ALCÂNTARA, R. L. C. Proposição de um modelo para a gestão da demanda: um estudo entre os elos atacadista e fornecedores de produtos de mercearia básica. Gestão \& Produção, v. 19, n. 4, p. 759-777, 2012. http://dx.doi.org/10.1590/S0104-530X2012000400008

MENTZER; J. T.; FONGHIN, J. H.; GOLICIC, S. L. Supply chain collaboration: enablers, impediments and Benefits. Supply Chain Management Review, v. 4, 2000 .

MENTZER, J. T. et al. Defining supply chain management. Journal of Business Logistics, v. 22, n. 2, 2001. http:// dx.doi.org/10.1002/j.2158-1592.2001.tb00001.x

MENTZER, J. T.; MOON, M. A. Sales forecasting management: a demand management approach. Thousand Oaks: Sage, 2005. PMCid:PMC1402344.

MENTZER, J. T. et al. Demand management. In: MENTZER, J. T.; MYERS, M. B.; STANK, T. P. Handbook of Global Supply Chain Management. Thousand Oaks: Sage, 2007. http://dx.doi.org/10.4135/9781412976169.n5

MILLIKEN, A. L. Sales \& operations planning: building the foundation. Journal of Business Forecasting, v. 27, p. 4-12, 2008.

MIN, S. et al. Supply chain collaboration: what's happening? The International Journal of Logistics Management, v. 16, n. 2, 2005. http://dx.doi. org/10.1108/09574090510634539

MIRANDA, G. J. Valor de empresas e medidas de desempenho econômico: um estudo em empresas atacadistas brasileiras. 2005. 177 f. Dissertação (Mestrado)-Universidade Federal de Uberlândia, Uberlândia, 2005.

PIRES, S. R. I. Gestão da cadeia de suprimentos: conceitos, estratégias, práticas e casos. São Paulo: Atlas, 2009.

RAINBIRD, M. Demand and supply chains: the value catalyst. International Journal of Physical Distribution and Logistics Management, v. 34, n. 3-4, 2004.

RANKING ABAD/Nielsen 2013. R\$ 178,5 Bilhões. Revista Distribuição, v. 244, n. 201, maio 2013.

REXHAUSEN, D.; PIBERNIK, R.; KAISER, G. Customerfacing supply chain practices: the impact of demand and distribution management on supply chain success. Journal of Operations Management, v. 30, p. 269-281, 2012. http://dx.doi.org/10.1016/j.jom.2012.02.001

SABATH, R. E.; FONTANELLA, J. The unfulfilled promise of supply chain collaboration. Supply Chain Management Review, v. 6, n. 4, 2002.

SEIFERT, D. Collaborative plannning, forcasting and replenishment: how to create a supply chain advantage. New York: AMACOM, 2003.

SILVA, A. L.; ALCÂNTARA, R. C. Mudanças nos relacionamentos e estratégias para melhor coordenação da cadeia de suprimentos. Revista de Administração, v. 36, n. 3, p. 49-58, 2001.

SIMATUPANG, T. M.; SRIDHARAN, R. The collaborative supply chain. International Journal of Logistics Management, v. 13, n. 1, p. 15-30, 2002. http://dx.doi. org/10.1108/09574090210806333

SIMATUPANG, T. M.; SRIDHARAN, R. Benchmarking supply chain collaboration: an empirical study. 
Benchmarking: An International Journal, v. 11, n. 5, p. 484-503, 2004.

STANK, T. P.; KELLER, S. B.; DAUGHERTY, P. J. Supply chain collaboration and logistical service performance. Journal of Business Logistics, v. 22, n. 1, p. 29-48, 2001. http://dx.doi.org/10.1002/j.2158-1592.2001.tb00158.x

TAYLOR, D. H. Demand management in agri-food supply chains: an analysis of the characteristics and problems and a framework for improvement. The International Journal of Logistics Management, v. 17, n. 2, p. 163-186, 2006. http://dx.doi.org/10.1108/09574090610689943

TAYLOR, D. H.; FEARNE, A. Towards a framework for improvement in the management of demand in agri-food supply chains. Supply Chain Management: An International Journal, v. 11, n. 5, p. 379-384, 2006.

TROQUE, W. A. Influência das práticas da gestão da cadeia de suprimentos sobre a gestão da demanda: um modelo de análise conceitual. 2003. 189 f. Dissertação (Mestrado)-Universidade Metodista de Piracicaba, Santa Bárbara D'Oeste, 2003.

VIEIRA, J.; YOSHIZAKI, H.; HO, L. Collaboration intensity in the Brazilian supermarket retail chain.
Supply Chain Management: An International Journal, v. 14, n. 1, p. 11-21, 2009.

VOLLMANN, T. E. et al. Manufacturing planning and control for supply chain management. Boston: Mcgraw-Hill, 2004.

VOLUNTARY INTERINDUSTRY COMMERCE SOLUTIONS - VICS. Linking CPFR and S\&OP: a roadmap to integrated business planning. 2010. Disponível em:

$<$ http://www.vics.org/docs/committees/cpfr/CPFR_SOP Guideline_Ver1.0Sep2010.pdf> Acesso em: 31 out. 2012.

WALTERS, D. Demand chain effectiveness supply chain efficiencies. Journal of Enterprise Information Management, v. 19, n. 3, p. 246-261, 2006. http:// dx.doi.org/10.1108/17410390610658441

WALTERS, D.; RAINBIRD, M. The demand chain as an integral component of the value chain. Journal of Consumer Marketing, v. 21, n. 7, p. 465-475, 2004. http://dx.doi.org/10.1108/07363760410568680

YIN, R. K. Estudo de caso: planejamento e métodos. Porto Alegre: Bookman, 2005. 